\title{
NEURONAL RESPONSES OF THE GLOBUS PALLIDUS TO SYSTEMIC ADMINISTRATION OF $d$-AMPHETAMINE: INVESTIGATION OF THE INVOLVEMENT OF DOPAMINE, NOREPINEPHRINE, AND SEROTONIN $^{1}$
}

\author{
DEBRA A. BERGSTROM ${ }^{2}$ AND JUDITH R. WALTERS
}

Experimental Therapeutics Branch, National Institute of Neurological and Communicative Disorders and Stroke, National Institutes of Health, Bethesda, Maryland 20205

\begin{abstract}
Systemic administration of $d$-amphetamine ( $d$-AMP) caused significant increases in the unit activity of spontaneously firing neurons in the rat globus pallidus. Intravenous injection of $0.2 \mathrm{mg} / \mathrm{kg}$ of $d$-AMP produced an average increase of $32 \%$ while a cumulative dose of $6.4 \mathrm{mg} / \mathrm{kg}$ of $d$-AMP increased cell firing $81 \%$ above base line control. The excitatory effects of $d$-AMP on pallidal cells were effectively blocked and reversed by haloperidol. Increasing intravenous doses of $l$-amphetamine ( $l$-AMP), totaling $12.8 \mathrm{mg} / \mathrm{kg}$, caused a slight excitation of pallidal neurons. The average maximum increase was $18.3 \%$. Minor rateelevating effects were also observed after systemic administration of desmethylimipramine and clonidine. The serotonin uptake inhibitor, fluoxetine, produced varied changes in firing frequencies. Pretreatment with reserpine and $\alpha$-methyl-p-tyrosine significantly attenuated the $d$-AMP-induced increase in pallidal activity. These results suggest that dopamine plays a prominent role in mediating the stimulatory effects of $d$-AMP on the firing rates of a population of globus pallidus cells in gallamine-paralyzed rats.
\end{abstract}

The pharmacology of the basal ganglia has received much attention in the past few years. In particular, the effects of dopamine and agents which interact with dopaminergic systems, such as $d$-amphetamine ( $d$-AMP), have been utilized in an effort to understand better the functioning of this important brain region. $d$-AMP is thought to increase the release and block the re-uptake of dopamine (Carlsson et al., 1966; Glowinski et al., 1966; Besson et al., 1969, 1971; Von Voigtlander and Moore, 1973). Release of dopamine by $d$-AMP has been demonstrated in the striatum (McKenzie and Szerb, 1968; Besson et al., 1969, 1971; Nieoullon et al., 1977a) and, more recently, in the region of the cell bodies and dendrites of the dopamine-containing neurons located in the substantia nigra (Nieoullon et al., 1977b). The ability of $d$-AMP to augment dopamine receptor stimulation by increasing the concentration of dopamine in the synaptic cleft has been associated with the drug's ability to inhibit the activity of spontaneously firing neurons in the striatum and tonically firing dopaminergic neurons in the pars compacta of the substantia nigra (Bunney et al., 1973a,

\footnotetext{
${ }^{1}$ The excellent assistance of Ms. Susan Bromley and Mr. Raymond Vane is greatly appreciated.

${ }^{2}$ Research Associate in the Pharmacology-Toxicology Program of the National Institute of General Medical Sciences, National Institutes of Health. To whom correspondence should be addressed at National Institutes of Health, 9000 Rockville Pike, Bldg. 36, Rm. 5A31, Bethesda, MD 20205.
}

b; Groves et al., 1974). The effect of $d$-AMP on these neurons has been shown to be readily reversed by systemic administration of haloperidol and other dopamine receptor antagonists and blocked, in the case of the dopamine neurons, by pretreatment with reserpine and $\alpha$-methyl-p-tyrosine (AMPT) or with haloperidol.

To explore the further consequences of blocking the uptake and increasing the release of dopamine, the effects of systemic administration of $d$-AMP on the spontaneously active neurons of the globus pallidus were investigated with electrophysiological techniques. It seemed likely that drug-induced changes in striatal neuronal activity would be reflected upon pallidal neurons as the globus pallidus is a principal efferent nucleus of the striatum. Also, recent biochemical and anatomical findings suggest that the activity of some pallidal neurons may be modulated directly by dopamine (Burt et al., 1976; Fields et al., 1977; Lindvall and Björklund, 1979).

\section{Materials and Methods}

Extracellular, single unit recordings were carried out in gallamine-paralyzed, locally anesthetized and artificially respired male, Sprague-Dawley rats (250 to 325 $\mathrm{gm}$ ) in strict accordance with the Guiding Principles in the Care and Use of Animals approved by the Council of the American Physiological Society. All surgical procedures were carried out under halothane anesthesia. A tracheotomy was performed and the trachea was intu- 
bated with a cannula. All incision sites and pressure points (including ear canals and nose bar contact areas) were thoroughly infiltrated with a long-acting local anesthetic (mepivacaine $\mathrm{HCl}$ ). The tracheal cannula was subsequently connected to a rodent respirator through which a mixture of halothane and room air was administered. Animals were placed in a stereotaxic apparatus. Gallamine triethiodide $(16 \mathrm{mg} / \mathrm{kg})$ was injected via a tail vein to cause paralysis of all skeletal musculature. Additional injections of gallamine were administered routinely throughout the experiment. All animals then were respired on room air at a rate adjusted to maintain an expired $\mathrm{CO}_{2}$ of 3.5 to $4.2 \%$ as measured by a $\mathrm{CO}_{2}$ analyzer. Eyedrops of a tetrahydrozoline $\mathrm{HCl}$ solution were applied intermittently to prevent discomfort due to corneal drying. Body temperature was monitored with a telethermometer and maintained at 36 to $38^{\circ} \mathrm{C}$ with an electric heating pad.

A 3-mm burr hole was drilled through the skull above the globus pallidus at a site $2.60 \mathrm{~mm}$ lateral to lambda and $7.30 \mathrm{~mm}$ anterior to the lambdoid suture. An electrode was passed through the hole to the level of the globus pallidus with a hydraulic microdrive. Electrode potentials were passed through a high input-impedance amplifier and monitored on an oscilloscope and audiomonitor. Electrode potentials were isolated to a signalto-noise ratio of 3:1 or more. Integrated firing rates were recorded by a rate meter and displayed as histogram plots of the number of electrode potentials counted in successive 10 -sec intervals on a strip chart recorder.

Single barrel recording electrodes were pulled from 2.0 $\mathrm{mm}$ glass capillary tubing $(1.0 \mathrm{~mm}$, I.D., Corning Glass Works, Corning, NY) which contained several strands of fiber glass (Tasaki et al., 1968). After being pulled, the micropipettes were filled with $1 \%$ Pontamine sky blue (GURR, High Wycombe, Bucks, United Kingdom) in 2 $\mathrm{M} \mathrm{NaCl}$ and the tips were broken back to a diameter of approximately 1 to $2 \mu \mathrm{m}$. The electrodes used in these studies had resistances between 3.6 and $6.0 \mathrm{megohms}$ (measured at $135 \mathrm{~Hz}$ ).

Spontaneously active cells with extracellular, biphasic action potentials of short duration (range, 0.53 to 1.52 msec; mean, $0.78 \pm 0.04, n=22$ ) in the frequency range of 10 to 90 spikes/sec were investigated. Pallidal cells displaying either constant firing patterns, irregular firing patterns, or bursting discharge patterns were included in this study.

Each animal was allowed to recover from the initial halothane anesthesia for at least $30 \mathrm{~min}$ before drug administration. After a 5-min period of base line activity was recorded, drugs were administered i.v. through a tail vein according to one of three dosage schedules. In cumulative dose-effect studies with $d$-AMP and $l$-amphetamine ( $l$-AMP), the drugs were administered at 2 -min intervals in increasing amounts so that each dose doubled the previous cumulative dose (i.e., 0.2., 0.2., 0.4., 0.8, 1.6, 3.2 , and $6.4 \mathrm{mg} / \mathrm{kg}$; total cumulative dose, $12.8 \mathrm{mg} / \mathrm{kg}$ ). In dose-response studies with desmethylimipramine (DMI) and fluoxetine, the drugs were given in successive $2.0 \mathrm{mg} / \mathrm{kg}$ doses up to a total cumulative dose of $10.0 \mathrm{mg} /$ $\mathrm{kg}$. In experiments with clonidine and in some of the experiments with $d$-AMP, a single injection of the drug was given. In experiments requiring catecholamine depletion and synthesis inhibition, rats were pretreated with reserpine $(1.5 \mathrm{mg} / \mathrm{kg}$, i.p., 18 to $24 \mathrm{hr}$ before recording) and AMPT ( $250 \mathrm{mg} / \mathrm{kg}$, i.p., 2 to $5 \mathrm{hr}$ before recording). In all experiments in which drugs were administered, only one cell per animal was studied. Where the data are expressed as the percentage of base line control, this percentage was determined by comparing the firing rates averaged over a 5 -min base line (pre-drug) period (defined as $100 \%$ ) with that observed in the six 10 -sec intervals occurring between 60 and $120 \mathrm{sec}$ after the drug was injected. This procedure allowed for comparison of group data despite individual neuronal differences with respect to pre-drug firing rate. The " $n$ 's" reported for the individual experiments indicate the number of cells (i.e., the number of animals) studied.

At the conclusion of each experiment, the animals received an anesthetic dose of chloral hydrate and were sacrificed. The site of the recording, which was marked by passing a $15 \mathrm{nA}$ anodal current through the electrode for about $15 \mathrm{~min}$, was identified by locating the Pontamine sky blue deposit after the brain was fixed, sectioned, mounted, and stained with cresyl violet. The cells recorded in these studies were located in the globus pallidus within the stereotaxic coordinates: anterior, 5910 to $6860 \mu \mathrm{m}$; lateral, 2.0 to $3.0 \mathrm{~mm}$; ventral, +0.4 to -1.6 $\mathrm{mm}$, according to König and Klippel (1970).

The data are expressed as the mean \pm the standard error of the mean. Differences between two means were analyzed using Student's $t$ test for grouped data with a criterion of significance of $p<0.05$ (Dixon and Massey, 1969).

The drugs used in these studies included: $d$-AMP sulfate (Sigma Chemical Co., St. Louis, MO), l-AMP sulfate (Smith, Kline \& French Laboratories, Philadelphia, PA), clonidine (Boehringer Ingelheim Ltd., Elmsford, NY), DMI hydrochloride (USV Pharmaceutical Corp., Tuckahoe, NY), fluoxetine (Eli Lilly \& Co., Indianapolis, IN), haloperidol (McNeil Laboratories, Fort Washington, PA), AMPT methyl ester hydrochloride (Aldrich Chemical Co., Milwaukee, WI), and reserpine (CIBA Pharmaceutical Co.,.Summit, NJ). Doses of drugs are given in terms of the weights of their salts.

\section{Results}

Effects of $d-A M P$ on firing rates of neurons in the globus pallidus. To examine the effect of $d$-AMP on the neuronal activity of pallidal cells, exponentially increasing amounts of $d$-AMP were administered i.v. at 2 -min intervals while the firing rates of individual neurons were recorded. Neuronal activities of 17 out of 19 cells were significantly increased ( $>30 \%$ above base line), the firing rate of one cell was unaffected ( $<30 \%$ from base line), and one cell showed a dose-related decrease in activity. Of the 17 cells that were stimulated by $d$-AMP, half showed dose-related increases in rate throughout the dose-response curve (Fig. 1A). The rest responded markedly to the lower doses of $d$-AMP $(0.8 \mathrm{mg} / \mathrm{kg}$ or less $)$ and maintained this enhanced rate throughout the remaining drug regimen (Fig. 1B). Overall, doses of $0.2 \mathrm{mg} / \mathrm{kg}$ caused an average increase of $32 \%$ while cumulative doses 


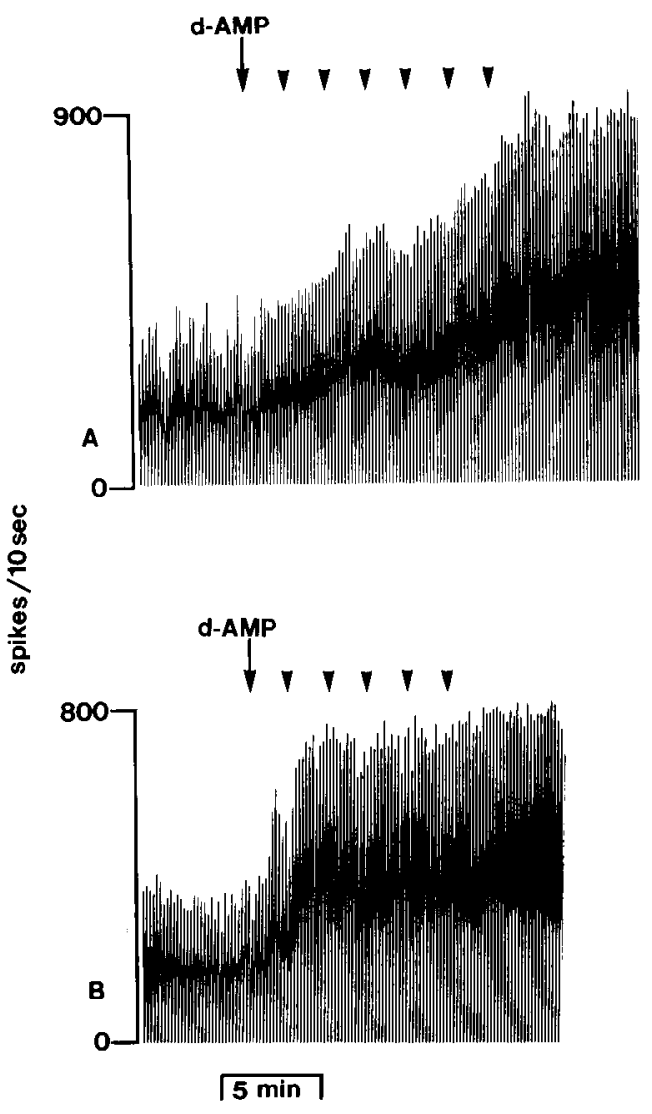

Figure 1. Effect of i.v. administration of $d$-amphetamine (dAMP) upon the single unit activity of spontaneously firing pallidal neurons. $\boldsymbol{A}, \boldsymbol{d}$-AMP was administered in exponentially increasing doses $(0.2,0.2,0.4,0.8,1.6,3.2$, and $6.4 \mathrm{mg} / \mathrm{kg}$; cumulative dose, $12.8 \mathrm{mg} / \mathrm{kg}$ ) at the times indicated by the arrows (2-min intervals). The response of this cell was typical of those cells which showed dose-related increases in rate in response to $d$-AMP. $B, A$ representative example of a population of cells that responded markedly to the lower doses of $d$ AMP and maintained this enhanced rate throughout the remaining drug regimen. $d$-AMP was administered as described above to a total cumulative dose of $6.4 \mathrm{mg} / \mathrm{kg}$.

of $6.4 \mathrm{mg} / \mathrm{kg}$ increased cell firing $81 \%$ above base line control (Fig. 2).

When the responses of the cells were analyzed with respect to their base line firing frequencies, it was noticed that the slower cells $(<50$ spikes/sec) were significantly more sensitive to the rate-increasing effects of $d$-AMP than were the faster cells ( $>50$ spikes/sec) (Fig. 3). At a cumulative dose of $0.8 \mathrm{mg} / \mathrm{kg}$ of $d$-AMP, the low frequency cells increased an average of $80 \%$ above base line in comparison to the $22 \%$ increase observed for the high frequency cells.

Duration of d-AMP's action and antagonism by haloperidol. To explore the duration of the rate-elevating effects of $d$-AMP, the discharges of pallidal units were monitored while animals were given a single dose of $d$ AMP $(3.2 \mathrm{mg} / \mathrm{kg})$ which, as a cumulative dose, had effectively increased cell firing in other animals. Of the eight cells recorded in animals given a single injection of $3.2 \mathrm{mg} / \mathrm{kg}$ of $d$-AMP, one cell was unaffected, one cell exhibited a transient $68 \%$ maximal increase in firing rate, and six cells showed increases in rate to more than $100 \%$ above base line control. The average maximum rate for these six units was $156.5 \pm 2.1 \%$ above base line (Fig. $4 A$ ). These six units were held for at least $17 \mathrm{~min}$ following drug administration; they showed no significant decrease in firing rate during this time. Three of these cells were monitored for 28 to $32 \mathrm{~min}$ after the drug injection, during which period $d$-AMP's rate-elevating effects were still maximally maintained. As illustrated in Figure $4 A$, the firing frequency of the neuron increased significantly within the first $60 \mathrm{sec}$ after drug administration and

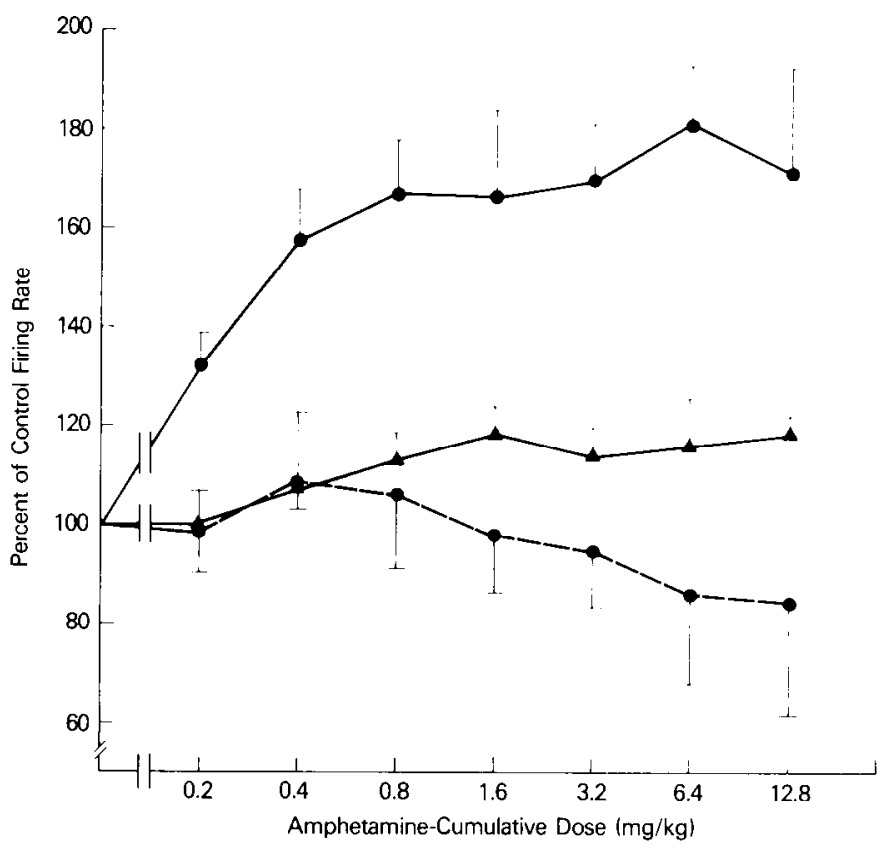

Figure 2. Cumulative dose-response curves of the percentage of excitation for neuronal firing rates of pallidal cells during i.v. administration of exponentially increasing doses of $d$-amphetamine ( $d$-AMP) (,$n=5$ to 17$)$ and $l$-amphetamine $(l$ AMP) $(\Delta-\Delta, n=10)$ to control rats. $d$-AMP was also administered to rats pretreated with reserpine (RES, $1.5 \mathrm{mg}$ / $\mathrm{kg}$, i.p., 18 to $24 \mathrm{hr}$ before recording) and AMPT (250 mg/kg, i.p., 2 to $5 \mathrm{hr}$ before recording) (--,$- n=8), d$-AMP and $l$ AMP were administered at 2-min intervals in a series of increasing doses so that each dose doubled the previous cumulative dose $(0.2,0.2,0.4,0.8,1.6,3.2$, and $6.4 \mathrm{mg} / \mathrm{kg}$; total dose, 12.8 $\mathrm{mg} / \mathrm{kg}$ ). In the dose-response studies with $d$-AMP, most cells were firing very rapidly after a cumulative dose of $6.4 \mathrm{mg} / \mathrm{kg}$ of $d$-AMP had been administered. Injection of the final dose of $6.4 \mathrm{mg} / \mathrm{kg}$ (to yield a cumulative dose of $12.8 \mathrm{mg} / \mathrm{kg}$ ) frequently resulted in an increase in the duration and a decrease in the amplitude of the extracellular action potential, suggesting that the spike-generating mechanisms of the neuron were being inactivated. Therefore, the number of experiments which were completed (i.e., cells monitored for the 2-min interval after the administration of the final dose) with a cumulative dose of 12.8 $\mathrm{mg} / \mathrm{kg}(n=5)$ is less than those completed with the lower doses of $d$-AMP ( $n=8$ to 17). Each point represents the mean excitation obtained at a given dose (calculated as described under "Materials and Methods"). The vertical bars represent the standard error of the mean. The responses obtained in reserpine and AMPT animals with $d$-AMP are significantly different $(p<0.05)$ from the responses obtained in control animals with $d$-AMP. In addition, in control animals, the responses observed with $l$-AMP are significantly different $(p<$ 0.05 ) from the responses obtained with $d$-AMP. 


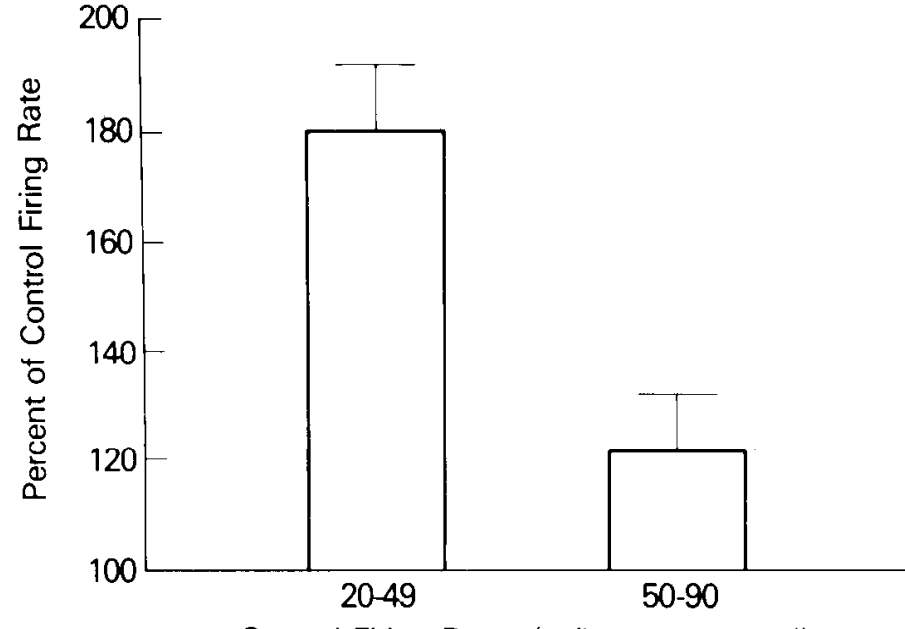

Control Firing Rates (spikes per second)

Figure 3. Effect of a cumulative dose of $0.8 \mathrm{mg} / \mathrm{kg}$ of $d$ amphetamine ( $d$-AMP) on pallidal neurons with low $(<50$ spikes/sec) and high (>50 spikes/sec) firing frequencies. Bars represent the means (expressed as the percentage of base line rate) and the standard error of the means for 13 low frequency cells and four high frequency cells. The means are significantly different $(p<0.05)$.

within the next $60 \mathrm{sec}$, the firing rate had attained $82 \%$ of its maximum response.

Additional experiments were performed to determine if the effects of $d$-AMP on pallidal activity could be blocked by pretreatment with a dopaminergic antagonist or reversed by subsequent administration of the antagonist. After a cell had been monitored for a 5 -min period, two injections of $0.2 \mathrm{mg} / \mathrm{kg}$ of haloperidol were given 2 min apart. After this treatment, subsequent injections of $d$-AMP $(3.2 \mathrm{mg} / \mathrm{kg})$ had little effect on pallidal cells $(n$ $=7$ ) (Fig. 4B). Over the 15-min time period following the administration of haloperidol and $d$-AMP, four cells displayed an average increase of $28.8 \pm 3.3 \%$ (range, 22.8 to $37.4 \%$ ) above base line control and three cells showed an average decrease of $22.7 \pm 3.1 \%$ (range, 16.9 to $27.5 \%$ ) below base line.

Another group of animals $(n=5)$ were given $d$-AMP (doses: 0.8 to $3.2 \mathrm{mg} / \mathrm{kg}$ ) until the monitored firing rate of the pallidal neuron was elevated 50 to $100 \%$ above base line control. Subsequent administration of haloperidol $(0.2$ to $0.6 \mathrm{mg} / \mathrm{kg})$ reversed the rate-enhancing effect of $d$-AMP and returned firing rates to base line control (Fig. $4 C$ ). However, in two animals given a cumulative dose of $12.8 \mathrm{mg} / \mathrm{kg}$ of $d$-AMP, haloperidol, in doses up to 1.6 or $3.2 \mathrm{mg} / \mathrm{kg}$, did not antagonize $d$-AMP's action.

Investigation of the effects of norepinephrine and serotonin on pallidal firing rates. To investigate the possibility that monoaminergic neurotransmitters other than dopamine might be involved in mediating the action of $d$-AMP on pallidal neurons, experiments were conducted with agents believed to preferentially potentiate or stimulate norepinephrine and serotonin systems. Since $l$-AMP appears to be as effective as $d$-AMP on the norepinephrine system but less effective than $d$-AMP on the dopamine system (Ferris et al., 1972; Harris and Baldessarini, 1973; Bunney et al., 1975), l-AMP was uti- lized to obtain an estimation of the involvement of norepinephrine in mediating the $d$-AMP-induced increase in pallidal firing. $l$-AMP, administered at 2 -min intervals $(0.2$ to $12.8 \mathrm{mg} / \mathrm{kg})$ in exponentially increasing amounts, caused a slight excitation of pallidal neurons (Fig. $5 A$ ). The response to $l$-AMP was very consistent among these cells whose frequencies were rate-matched with those of the neurons in the $d$-AMP study (average rates (spikes/ sec): $36 \pm 5, n=10$ and $41 \pm 4, n=17$, respectively). The average maximum increase of the 10 units tested was $18.3 \pm 4.9 \%$ (Fig. 2).

Additional studies were performed with DMI to examine the consequences of inhibiting the uptake of norepinephrine on pallidal activity. Intravenous administration of DMI also produced an increase in the firing rates of pallidal neurons $(n=9)$ (Fig. $5 B)$. The average increase observed in animals receiving a cumulative dose of 10 $\mathrm{mg} / \mathrm{kg}$ of DMI was $24.4 \pm 8.5 \%$.

Consistent with the results obtained with $l$-AMP and DMI were those obtained with clonidine. A dose of clonidine $(100 \mu \mathrm{g} / \mathrm{kg})$, high enough to have a stimulatory effect on postsynaptic norepinephrine receptors in the central nervous system (Andén et al., 1970; Svensson et al., 1975), was administered to animals once a pallidal unit was monitored. During the 5 -min period after the administration of clonidine, pallidal activity increased by an average of $25.8 \pm 12.4 \%(n=7)$ (Fig. $5 C$ ). The effect of this drug on the firing rates of individual cells was variable, however. Of these seven cells, three cells were unaffected $(3.0 \pm 6.2 \%$ change from base line control) and four cells were stimulated $(47.4 \pm 12.6 \%$ increase above base line) by systemic administration of clonidine.

Since a number of studies have shown that AMP affects the serotonin system (Fuxe and Ungerstedt, 1970; $\mathrm{Ng}$ et al., 1970; Azzaro and Rutledge, 1973; Svensson et al., 1975; Sloviter et al., 1978), the next series of experiments examined the effects of serotonin on pallidal activity. The effect of the serotonin uptake inhibitor, fluoxetine, on seven pallidal units varied greatly. After administration of $10 \mathrm{mg} / \mathrm{kg}$ of fluoxetine, three cells were unaffected $(0.5 \pm 1.6 \%$ changes from base line), three cells were significantly excited $(64.5 \pm 11.7 \%$ above base line), and one cell was significantly inhibited $(31.8 \%$ below base line) (Fig. $5 D$ ).

Effectiveness of d-AMP after pretreatment with reserpine and $A M P T$. In order to examine the dependence of $d$-AMP's effects on catecholamine synthesis and release, the firing rates of pallidal cells were recorded in rats pretreated with reserpine $(1.5 \mathrm{mg} / \mathrm{kg}$, i.p., 18 to $24 \mathrm{hr}$ before recording) and AMPT (250 mg/kg, i.p., 2 to $5 \mathrm{hr}$ before recording). Interruption of catecholamine synthesis and release effectively attenuated the rate-elevating effects of $d$-AMP on pallidal neurons in eight out of nine animals examined (Fig. 2). In one of the animals examined, $d$-AMP, at cumulative doses of 6.4 and $12.8 \mathrm{mg} / \mathrm{kg}$, caused a marked increase in neuronal firing, a response atypical of the effects observed in the other eight animals. It was noted that the symptoms which typically accompany reserpine treatment were less apparent in this animal than in the other eight animals. Therefore, this animal may have been less effectively depleted of catecholamines. 

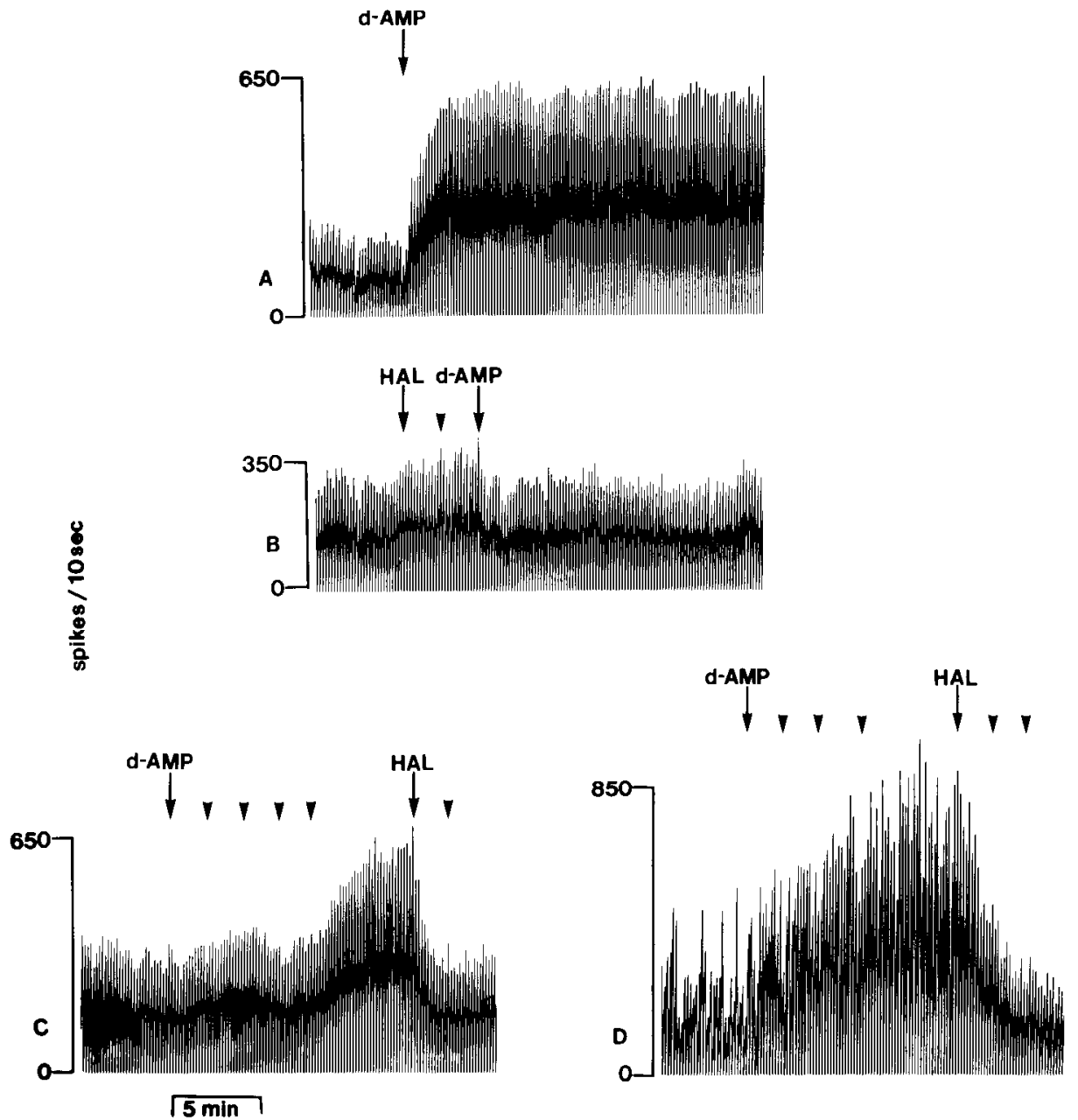

Figure 4. Effect of $d$-amphetamine (d-AMP) and haloperidol (HAL) on pallidal firing rates. $A$, A single injection of $3.2 \mathrm{mg} / \mathrm{kg}$ of $d$-AMP (i.v.) significantly increased the firing rate of this cell. The duration of the rate-elevating effect lasted throughout the recording time of $21 \mathrm{~min}$ post-injection. $B$, Prior administration of $\mathrm{HAL}(0.2 \mathrm{mg} / \mathrm{kg}$, i.v., given twice at 2 -min intervals) effectively blocked the action of $d$-AMP $(3.2 \mathrm{mg} / \mathrm{kg}$, i.v.) on pallidal activity. $C$ and $D, d$-AMP was administered in exponentially increasing doses (cumulative doses, 3.2 and $1.6 \mathrm{mg} / \mathrm{kg}$ ) until the monitored firing rates of the pallidal neurons were elevated 50 to $100 \%$ above base line control. Subsequent administration of $\mathrm{HAL}$ (repeated doses of $0.2 \mathrm{mg} / \mathrm{kg}$, i.v.) reversed the increase in firing frequency back to base line control in pallidal cells, which displayed either constant $(C)$ or irregular $(D)$ firing patterns.

\section{Discussion}

The present study demonstrates that systemic administration of $d$-AMP increases markedly the activity of the spontaneously firing neurons of the globus pallidus in gallamine-paralyzed rats. The firing rates of approximately $90 \%$ of the units tested increased by at least $30 \%$ in response to $d$-AMP and $54 \%$ of these units doubled their pre-drug base line firing frequency after doses of 3.2 $\mathrm{mg} / \mathrm{kg}$ or less. Responsive cells in the globus pallidus were not of one particular type; that is, neurons with recurrent periods of high frequency discharge separated by intervals of silence or low frequency discharge (irregular patterns) and neurons with rather constant high frequency or low frequency firing rates were all sensitive to $d$-AMP's action. However, neurons with the highest frequencies ( $>50$ spikes/sec) were significantly less sensitive to the drug's rate-elevating effects than were the low frequency neurons $(<50$ spikes/sec). Whether the high frequency cells constituted a subpopulation of pallidal neurons which were less sensitive to $d$-AMP's effects or whether they were already firing close to their maximum frequency and, therefore, were unable to increase their firing rates significantly more remained unanswered.

When an effective dose of $d$-AMP was given, the response of the pallidal units occurred with little delay and persisted for as long as the neurons were monitored (17 to $32 \mathrm{~min}$ ). Similar time courses have been reported for the effects of this agent on other brain regions. Bunney and colleagues (1973b) reported that the dopaminergic neurons of the substantia nigra were significantly inhibited by $d$-AMP within $30 \mathrm{sec}$ after intravenous injection and that these neurons recovered to only $25 \%$ of their original firing rates after $30 \mathrm{~min}$; Groves and Rebec (1977) observed that the depression in firing rates of neurons in the caudate lasted 70 to $120 \mathrm{~min}$ in response to $d$-AMP administration. In addition, the doses of $d$ AMP required to stimulate neurons in the globus pallidus and inhibit striatal and nigral dopamine cells are comparable. Doses of $d$-AMP used in the electrophysiological experiments described above are also in the same range 

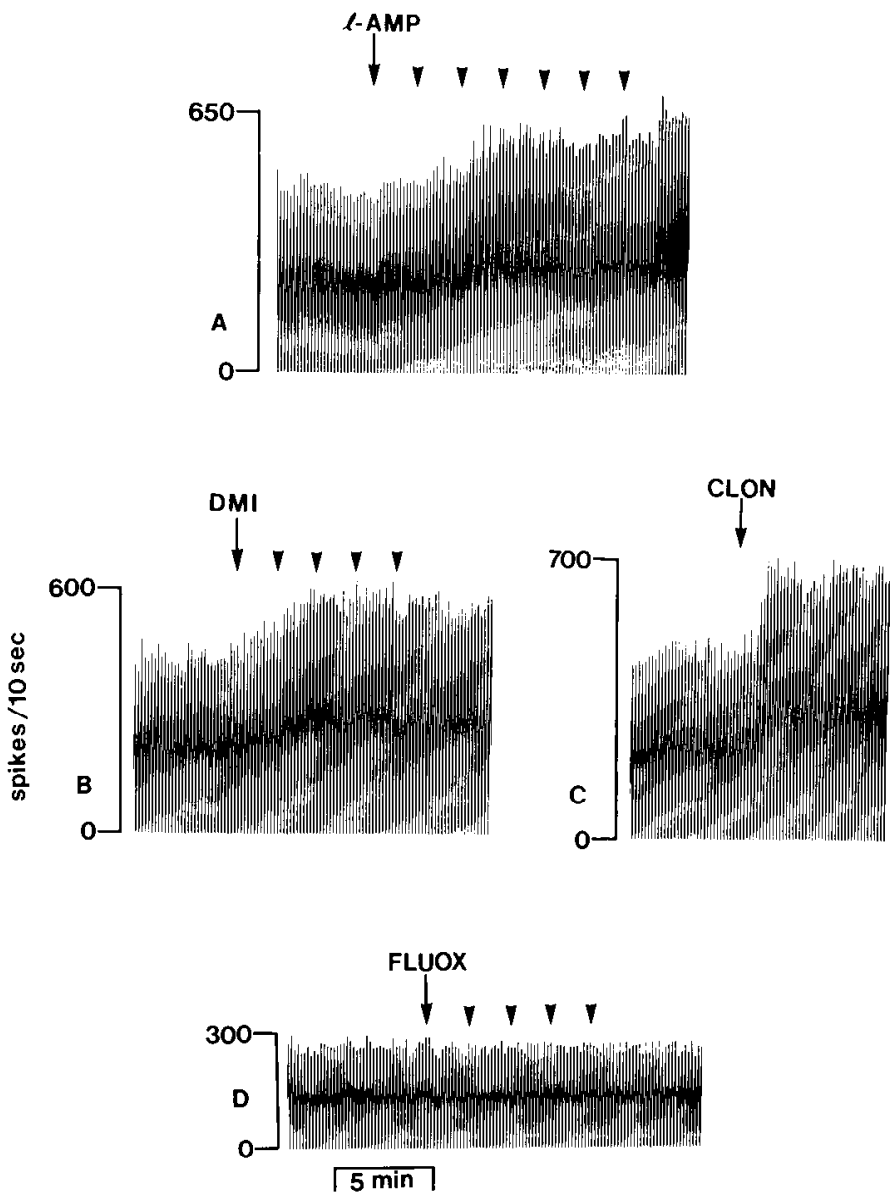

Figure 5. Effect of noradrenergic and serotonergic agents on pallidal firing rates. $A$, Effect of $l$-amphetamine $(l$-AMP) on a pallidal neuron. $l$-AMP was administered in increasing increments at 2-min intervals so that each dose doubled the previous cumulative dose (i.e., $0.2,0.2,0.4,0.8,1.6,3.2$, and $6.4 \mathrm{mg} / \mathrm{kg}$; cumulative dose, $12.8 \mathrm{mg} / \mathrm{kg}$ ). $B$, Effect of desmethylimipramine (DMI) on a pallidal neuron. DMI was administered in 2 $\mathrm{mg} / \mathrm{kg}$ increments at 2-min intervals to a total cumulative dose of $10 \mathrm{mg} / \mathrm{kg}$. C, Effect of clonidine (CLON) on a pallidal neuron. A single dose of $100 \mu \mathrm{g} / \mathrm{kg}$ of clonidine was administered to this pallidal unit. Four of the seven cells recorded responded in a similar manner to the i.v. administration of clonidine; the remaining cells were not affected. $D$, Effect of fluoxetine (FLUOX) on pallidal neurons. Fluoxetine was administered in $2 \mathrm{mg} / \mathrm{kg}$ increments at 2-min intervals to a total cumulative dose of $10 \mathrm{mg} / \mathrm{kg}$. The firing rate of this cell was unaffected by fluoxetine. This response was typical of three of the seven cells recorded during i.v. fluoxetine administration; of the remaining cells recorded, three were stimulated and one was inhibited.

of the doses of $d$-AMP employed to detect changes in biochemical (i.e., inhibition of dopamine neuronal uptake, increase of dopamine release) (Coyle and Snyder, 1969; Von Voigtlander and Moore, 1973) and behavioral (locomotor activity and stereotypy) (Taylor and Snyder, 1971; Costa et al., 1972) processes. These relationships support the idea that the electrophysiological, biochemical, and behavioral effects of $d$-AMP are related.

The studies presented here also provide some insight into the mechanism(s) involved in the excitatory action of $d$-AMP in the globus pallidus. In animals treated with reserpine and AMPT, pallidal cells were not stimulated by $d$-AMP. This finding suggests that $d$-AMP does not have a significant direct action on catecholamine receptors and requires the presence and continued synthesis of catecholamines to produce its effects. The observation that haloperidol, a dopamine receptor blocker, effectively blocks and reverses the rate-elevating effects of $d$-AMP suggests that the excitatory effects of $d$-AMP on pallidal neurons are mediated through stimulation of dopamine receptors. Comparable observations and conclusions, based on electrophysiological recordings, have been made for $d$-AMP's inhibitory action on nigral dopaminergic neurons (Bunney and Aghajanian, 1973; Bunney et al., $1973 b)$. In addition, systemic administration of the dopaminergic agonist, apomorphine, causes a dose-related, haloperidol-reversible increase in the firing of neurons in the globus pallidus (Bergstrom and Walters, 1980). In view of these findings, the significant dopaminergic innervation of areas which send major projections to the pallidus (Andén et al., 1964; Dahlström and Fuxe, 1964; Campbell et al., 1979; Meibach and Katzman, 1979) and the presence of some dopamine in the globus pallidus (Versteeg et al., 1976), the involvement of dopamine in the excitatory effects of systemic administration of $d$ AMP on pallidal cells seems likely.

Further experimentation dealt with the participation of other monoamines in mediating the actions of $d$-AMP. Since $d$-AMP is effective in altering the activity of norepinephrine as well as dopamine neuronal system, $l$-AMP, an agent which is a more potent inhibitor of norepinephrine neurons than of dopamine neurons (Bunney et al., 1975), seemed an excellent tool with which to examine the relative roles of norepinephrine and dopamine in producing $d$-AMP's effects in the globus pallidus. The minor rate-increasing effects that were seen with $l$-AMP administration indicate that the excitement seen with $d$-AMP can be attributed to inhibition of uptake and increase in release of dopamine. This inference, together with the results obtained with DMI and clonidine, suggests that norepinephrine is not the major catecholamine responsible for the consistent, dramatic pallidal responses induced by $d$-AMP. The low concentrations of norepinephrine in the striatal and pallidal nuclei also argue against a proposal for a prominent role of norepinephrine here (Versteeg et al., 1976). Similarly, the idea that serotonin does not play a major role in $d$-AMP's action is supported by the varied results obtained with the serotonin uptake inhibitor, fluoxetine. The effects of $d$-AMP on the pallidal units also seem unlikely to be the result of peripheral sympathetic changes since changes in firing rates do not correlate well with alterations in heart rate and blood pressure (D. A. Bergstrom and J. R. Walters, unpublished observations). In summary, these observations imply that the excitatory action of $d$-AMP in the globus pallidus is mediated by monoamines, in particular, by dopamine with some possible minor contribution made by norepinephrine and serotonin.

There are several possible anatomical sites where dopamine could act to mediate $d$-AMP's action on the globus pallidus. One possibility is that $d$-AMP acts at dopamine terminals in the globus pallidus itself. Recently, Lindvall and Björklund (1979) detected the pres- 
ence of a dopaminergic projection to the globus pallidus originating in the substantia nigra. This observation of a nigropallidal tract supports and extends the autoradiographic findings of Fallon and Moore (1978). The presence of dopamine receptors (Burt et al., 1976; Fields et al., 1977) and dopamine (Versteeg et al., 1976) in the globus pallidus, together with the histological detection of a dopaminergic nigropallidal pathway, suggests the possibility that $d$-AMP is interacting with dopaminergic processes in the globus pallidus to produce excitatory effects on these neurons. Excitatory neuronal effects in the globus pallidus have been observed with iontophoretic application of dopamine. York (1970) reported that dopamine increased the discharge frequency of $47 \%$ of the neurons tested in the cat globus pallidus. Similar dopamine-mediated increases in neuronal firing have been observed in the caudate (Norcross and Spehlman, 1978) and putamen (York, 1970). Kitai and colleagues (1976) also reported that dopamine has an initial depolarizing, excitatory action on caudate neurons.

It is also possible that some or all of the alterations in pallidal firing induced by $d$-AMP are mediated indirectly through the striatum. Since the globus pallidus receives substantial input from the striatum (for review, see Graybiel and Ragsdale, 1979), the increase of pallidal firing rates noted after systemic administration of $d$-AMP may result from effects of AMP in the striatum. Indeed, systemic administration of $d$-AMP causes a marked reduction in the firing frequencies of striatal neurons (Groves et al., 1974; Groves and Rebec, 1977). Also dopamine, applied iontophoretically, inhibits striatal neuronal firing (Bloom et al., 1965; McLennan and York, 1967; Connor, 1970; Feltz and de Champlain, 1972; Skirboll et al., 1979; Herrling and Hull, 1980). Observations obtained from stimulation experiments suggest that the striatum exerts an inhibitory influence on pallidal neurons; stimulation of striatal neurons or of the striatofugal fibers typically produces excitation and inhibition (EPSP-IPSP sequence) or only inhibition (IPSP) of pallidal neurons (Malliani and Purpura, 1967; Noda et al., 1968; Levine et al., 1974; Ohye et al., 1976). Thus, it may well be that inhibition of striatal activity and, therefore, a reduction of striatal inhibitory influences on pallidal activity initiate excitatory responses in a population of neurons in the globus pallidus.

Other brain components, such as the subthalamic nucleus which may receive a dopaminergic innervation (Campbell et al., 1979; Meibach and Katzman, 1979), send afferents to the globus pallidus (for review, see Graybiel and Ragsdale, 1979), and be receptive to the modulatory influences of dopamine (Campbell and Weight, 1978; Brown et al., 1979), may also contribute to the effects of $d$-AMP on the globus pallidus.

In summary, this study demonstrates that systemic administration of $d$-AMP increases significantly the firing frequency of a population of spontaneously active neurons in the rat globus pallidus. This rate-enhancing effect appears to be mediated mainly through the actions of dopamine.

\section{References}

Andén, N.- E., A. Carlsson, A. Dahlström, K. Fuxe, N.- A. Hillarp, and N. Larrson (1964) Demonstration and mapping out of nigro-neostriatal dopamine neurons. Life Sci. 3: 523530.

Andén, N.- F., H. Corrodi, K. Fuxe, B. Hökfelt, T. Hökfelt, C. Rydin, and 'T. Svensson (1970) Evidence for a central noradrenaline receptor stimulation by clonidine. Life Sci. 9: $513-$ 523.

Azzaro, A. J., and C. O. Rutledge (1973) Selectivity of release of norepinephrine, dopamine and 5-hydroxytryptamine by amphetamine in various regions of rat brain. Biochem. Pharmacol. 22: 2801-2813.

Bergstrom, D. A., and J. R. Walters (1980) Effects of dopaminergic, cholinergic and GABAergic drugs upon the activity of rat globus pallidus neurons. Soc. Neurosci. Abstr. 6: 273.

Besson, M. J., A. Cheramy, and J. Glowinski (1969) Effects of amphetamine and desmethylimipramine on amine synthesis and release in central catecholamine-containing neurons. Eur. J. Pharmacol. 7: 111-114.

Besson, M. J., A. Cheramy, P. Feltz, and J. Glowinski (1971) Dopamine: Spontaneous and drug induced release from caudate nucleus. Brain Res. 32: 407-424.

Bloom, F. E., E. Costa, and G. C. Salmoiraghi (1965) Anesthesia and the responsiveness of individual neurons of the caudate nucleus of the cat to acetylcholine, norepinephrine and dopamine administered by microelectrophoresis. J. Pharmacol. Exp. Ther. 150: 244-252.

Brown, L. L., M. H. Makman, L. I. Wolfson, B. Dvorkin, C. Warner, and R. Katzman (1979) A direct role of dopamine in the rat subthalamic nucleus and an adjacent intrapenduncular area. Science 206: 1416-1418.

Bunney, B. S., and G. K. Aghajanian (1973) Electrophysiological effects of amphetamine on dopaminergic neurons. In Frontiers of Catecholamine Research, E. Usdin and S. H. Snyder, eds., pp. 957-962, Pergamon Press, New York.

Bunney, B. S., G. K. Aghajanian, and R. H. Roth (1973a) Comparison of effects of L-dopa, amphetamine and apomorphine on firing rate of rat dopaminergic neurons. Nature New Biol. 245: 123-125.

Bunney, B. S., J. R. Walters, R. H. Roth, and G. K. Aghajanian (1973b) Dopaminergic neurons: Effect of antipsychotic drugs and amphetamine on single cell activity. J. Pharmacol. Exp. Ther. 185: 560-571.

Bunney, B. S., J. R. Walters, M. J. Kuhar, R. H. Roth, and G. K. Aghajanian (1975) D- \& L-amphetamine stereoisomers: Comparative potencies in affecting the firing of central dopaminergic and noradrenergic neurons. Psychopharmacol. Commun. 1: 177-190.

Burt, D. R., I. Creese, and S. H. Snyder (1976) Properties of tritiated haloperidol and tritiated dopamine binding associated with dopamine receptors in calf brain membranes. Mol. Pharmacol. 12: 800-812.

Campbell, G. A., and F. F. Weight (1978) Action of microiontophoretic administration of dopamine on subthalamic nucleus neurons in the rat. Soc. Neurosci. Abstr. 4: 442.

Campbell, G. A., M. J. Eckardt, and F. F. Weight (1979) Afferent connections to the subthalamic nucleus of rat studied with horseradish peroxidase. Soc. Neurosci. Abstr. 5: 68.

Carlsson, A., K. Fuxe, B. Hamberger, and M. Lindqvist (1966) Biochemical and histochemical studies on the effects of imipramine-like drugs and (+)-amphetamine on central and peripheral catecholamine neurons. Acta Physiol. Scand. 55: 95-105.

Connor, J. D. (1970) Caudate nucleus neurons: Correlation of the effects of substantia nigra stimulation with iontophoretic dopamine. J. Physiol. (I ond.) 208: 691-703.

Costa, E., A. Groppetti, and M. K. Naimzada (1972) Effects of amphetamine on the turnover rate of brain catecholamines and motor activity. Br. J. Pharmacol. 44: 742-751.

Coyle, J. T., and S. H. Snyder (1969) Catecholamine uptake by synaptosomes in homogenates of rat brain: Stereospecificity 
in different areas. J. Pharmacol. Exp. Ther. 170: 221-231.

Dahlström, A., and K. Fuxe (1964) Evidence for the existence of monoamine-containing neurons in the central nervous system. Acta Physiol. Scand. (Suppl. 232) 62: 1-55.

Dixon, W. J., and F. J. Massey, Jr. (1969) Introduction to Statistical Analysis, McGraw-Hill Book Co., New York.

Fallon, J. H., and R. Y. Moore (1978) Catecholamine innervation of the basal forebrain. IV. Topography of the dopamine projection to the basal forebrain and neostriatum. J. Comp. Neurol. 180: 545-580.

Feltz, P., and J. de Champlain (1972) Enhanced sensitivity of caudate neurons to microiontophoretic injections of dopamine in 6-hydroxydopamine treated cats. Brain Res. 43: 601605.

Ferris, R. H., F. L. M. Tang, and R. S. Maxwell (1972) A comparison of the capacities of isomers of amphetamine, deoxypiradol and methylphenidate to inhibit the uptake of tritiated catecholamines into rat cerebral cortex slices, synaptosomal preparations of rat cerebral cortex, hypothalamus and striatum and into adrenergic nerves of rabbit aorta. J. Pharmacol. Exp. Ther. 181: 407-416.

Fields, J. Z., T. D. Reisine, and H. I. Yamamura (1977) Biochemical demonstration of dopaminergic receptors in rat and human brain using $\left[{ }^{3} \mathrm{H}\right]$-spiroperidol. Brain Res. 136: 578584.

Fuxe, K., and U. Ungerstedt (1970) Histochemical, biochemical and functional studies on central monamine neurons after acute and chronic amphetamine administration. In Amphetamines and Related Compounds, E. Costa and S. Garattini, eds., pp. 257-288, Raven Press, New York.

Glowinski, J., J. Axelrod, and L. Iversen (1966) Regional studies of catecholamines in the rat brain. IV. Effects of drugs on the disposition and metabolism of $\mathrm{H}^{3}$-norepinephrine and $\mathrm{H}^{3}$ dopamine. J. Pharmacol. Exp. 'Ther. 153: 30-41.

Graybiel, A. M., and C. W. Ragsdale (1979) Fiber connections of the basal ganglia. In Development and Chemical Specificity of Neurons, Progress in Brain Research, M. Cuenod, G. W. Kruetzberg, and F. E. Bloom, eds., Vol. 51, pp. 239-283, Elsevier/North-Holland Biomedical Press, Amsterdam.

Groves, P. M., and G. V. Rebec (1977) Changes in neuronal activity in the neostriatum and reticular formation following acute or long-term amphetamine administration. In Cocaine and Other Stimulants, E. H. Ellinwood and M. M. Kilbey, eds., pp. 269-301, Plenum Press, New York.

Groves, P. M., G. V. Rebec, and D. S. Segal (1974) The action of $D$-amphetamine on spontaneous activity in the caudate nucleus and reticular formation of the rat. Behav. Biol. 11: $33-47$.

Harris, J. E., and R. J. Baldessarini (1973) Uptake of $\left[{ }^{3} \mathrm{H}\right]$ catecholamines by homogenates of rat corpus striatum and cerebral cortex: Effects of amphetamine analogues. Neuropharmacology 12: 669-679.

Herrling, P. L., and C. D. Hull (1980) Iontophoretically applied dopamine depolarizes and hyperpolarizes the membrane of cat caudate neurons. Brain Res. 192: 441-462.

Kitai, S. T., M. Sugimori, and J. D. Kocsis (1976) Excitatory nature of dopamine in the nigro-caudate pathway. Exp. Brain Res. 24: 351-363.

König, J. F. R., and R. A. Klippel (1970) The Rat Brain: A Stereotaxic Atlas, R. E. Krieger Publishing Co. Inc., New York.

Levine, M. S., C. D. Hull, and N. A. Buchwald (1974) Pallidal and entopeduncular intracellular responses to striatal, cortical, thalamic, and sensory inputs. Exp. Neurol. 44: 448-460.

Lindvall, O., and A. Björklund (1979) Dopaminergic innervation of the globus pallidus by collaterals from the nigrostriatal pathway. Brain Res. 172: 169-173.

Malliani, A., and D. P. Purpura (1967) Intracellular studies of the corpus striatum II. Patterns of synaptic activities in lenticular and entopeduncular neurons. Brain Res. 6: 341354.

McKenzie, G. M., and J. C. Szerb (1968) The effect of dihydroxyphenylalanine, pheniprazine and dextroamphetamine on the in vivo release of dopamine from the caudate nucleus. J. Pharmacol. Exp. Ther. 162: 302-308.

McLennan, H., and D. H. York (1967) The action of dopamine on neurones of the caudate nucleus. J. Physiol. (Lond.) 189: 393-402.

Meibach, R. C., and R. Katzman (1979) Catecholaminergic innervation of the subthalamic nucleus: Evidence for a rostral continuation of the A9 (substantia nigra) dopaminergic cell group. Brain Res. 173: 364-368.

Ng, K. Y., T. N. Chase, and I. J. Kopin (1970) Drug-induced release of ${ }^{3} \mathrm{H}$-norepinephrine and ${ }^{3} \mathrm{H}$-serotonin from brain slices. Nature 28: 468-469.

Nieoullon, A., A. Cheramy, and J. Glowinski (1977a) An adaptation of the push-pull cannula method to study the in vivo release of $\left[{ }^{3} \mathrm{H}\right]$-dopamine synthesized from $\left[{ }^{3} \mathrm{H}\right]$-tyrosine in the cat caudate nucleus: Effects of various physical and pharmacological treatments. J. Neurochem. 28: 819-828.

Nieoullon, A., A. Cheramy, and J. Glowinski (1977b) Release of dopamine in vivo from cat substantia nigra. Nature 266: 375 377.

Noda, H., S. Manohar, and W. R. Adey (1968) Responses of cat pallidal neurons to cortical and subcortical stimuli. Exp. Neurol. 20: 586-610.

Norcross, K., and R. Spehlman (1978) A quantitative analysis of the excitatory and depressant effects of dopamine on the firing of caudatal neurons: Electrophysiological support for the existence of two distinct dopamine-sensitive receptors. Brain Res. 156: 168-174.

Ohye, C., C. Le Guyader, and J. Feger (1976) Responses of subthalamic and pallidal neurons to striatal stimulation: An extracellular study on awake monkeys. Brain Res. 111: 241252.

Skirboll, L. R., A. A. Grace, and B. S. Bunney (1979) Dopamine auto- and postsynaptic receptors: Electrophysiological evidence for differential sensitivity to dopamine agonists. Science 206: 80-82.

Sloviter, R. S., E. G. Drust, and J. D. Connor (1978) Evidence that serotonin mediates some behavioral effects of amphetamine. J. Pharmacol. Exp. Ther. 206: 348-352.

Svenson, T. H., B. S. Bunney, and G. K. Aghajanian (1975) Inhibition of both noradrenergic and serotonergic neurons in brain by the alpha-adrenergic agonist clonidine. Brain Res. 92: 291-306.

Tasaki, K., U. Tsukahara, S. Ito, M. J. Wayner, and W. Y. Yu (1968) A simple, direct and rapid method for filling microelectrodes. Physiol. Behav. 3: 1009-1010.

Taylor, K. M., and S. H. Snyder (1971) Differential effects of Dand L-amphetamine on behavior and on catecholamine disposition in dopamine and norepinephrine containing neurons of rat brain. Brain Res. 28: 295-309.

Versteeg, D. H. G., J. van der Gugten, W. de Jong, and M. Palkovits (1976) Regional concentrations of noradrenaline and dopamine in rat brain. Brain Res. 113: 563-574.

Von Voigtlander, P. F., and K. E. Moore (1973) Involvement of nigrostriatal neurons in the in vivo release of dopamine by amphetamine, amantadine and tyramine. J. Pharmacol. Exp. Ther. 184: 542-552.

York, D. H. (1970) Possible dopaminergic pathway from substantia nigra to putamen. Brain Res. 20: 233-249 